\title{
End-users' knowledge, attitude, and behavior towards safe use of pesticides: a case study in the Guanting Reservoir area, China
}

\author{
Hong Zhang $\cdot$ Yonglong Lu
}

Received: 27 March 2007 / Accepted: 11 July 2007 / Published online: 5 September 2007

(C) Springer Science+Business Media B.V. 2007

\begin{abstract}
Pesticides are widely used in China for crop protection. However, the use of some highly toxic and accumulative pesticides has led to serious pollution to the environment. The knowledge that end-users of pesticides have about hazards is important for the prevention of acute poisoning. Moreover, farmers, especially those who purchase and use pesticides, often make important and long-standing impacts on the local ecosystem and environment. In this study, a specially designed questionnaire was used to collect information on their knowledge, attitude, and behavior related to pesticides in the Guanting Reservoir area, north of China. Most pesticide end-users reported that they took incomplete preventive measures for lack of extensive pesticide knowledge and information. Pesticide information, instruction, and training among farmers should be promoted, and governmental intervention is needed to ensure proper management regarding public health risks and environmental hazards.
\end{abstract}

H. Zhang

School of Environmental Science and Resources, Shanxi University, Taiyuan 030006, China

H. Zhang · Y. Lu ( $\square)$

Research Center for Eco-Environmental Sciences, Chinese Academy of Sciences, Beijing 100085, China e-mail: yllu@rcees.ac.cn
Keywords Farm interview - Safe pesticide use · Pesticide management - Questionnaire

\section{Introduction}

Pesticides are the primary method of pest control in developing countries. The benefit of pesticides to farms is obvious and direct, while its potential harm to humanity and the environment is often overlooked. Reliance on pesticides as the primary or sole means of pest control, however, may not be the most profitable or sustainable strategy, and may have a number of harmful side effects. Introducing pesticides into the environment can influence the target and non-target organisms through environmental media such as soil, water, and air. Many predators and parasites are killed through the application of pesticides. This causes the balance between pests and their natural predators to be broken. Thus, in the battle against pests, pesticide is a double-edged sword.

Pesticides are widely used in China for crop protection. Some highly toxic and bioaccumulative pesticides have caused serious pollution of soil, air, water, sediment, and food, often being biomagnified through the food chain to affect the health of individual organisms at higher trophic levels (Gomes et al. 1999). The use of chlorinated pesticides was formally phased out in China in 1983. At the same time, the government established a series of rules and regulations intended to address the management, 
production, and use of pesticides within the country. Despite the existence of a list of officially forbidden pesticides, government control and law enforcement are still weak (Zhang et al. 2005a, b). Banned products are available by illegal means and are used by the untrained public regardless of any health and ecological toxicity risks.

Past research on pesticide effects in China has been primarily concerned with their toxicity, contamination, and degradation, as well as their impact on animals and human populations living in the surroundings. However, there has been little study of the knowledge, attitude, and perceptions of the local people who use the pesticides. The decision-making process may be thought of as a series of interconnected steps, leading from the recognition of a problem and the identification of potential solutions to the selection and adaptation of an appropriate strategy (Sewell 1973). The outcome of the decision-making process is affected considerably by the perceptions and attitudes of the various participants in the process (White 1966). Success in decision-making depends not only on government support and the local management organizations, it also depends on the reaction and involvement of the local population.

Farmers' knowledge of hazards is important for the prevention of acute poisoning. Erroneous beliefs can seriously impair workers' capacity to protect themselves against risks (Koh and Jeyaratnam 1996). When taking into account differences in socioeconomic levels, global education, and nationality, the knowledge of pesticide users and distributors are different (Pascale et al. 2004). Moreover, farmers, especially those who purchase and use pesticides, often make an important and long-standing impact on the local ecosystem and environment. Thus, systematically conducted research to understand local populations living in or adjacent to areas where pesticides are used might offer new insights (Salameh 2004).

The objective of our study was to collect information on the awareness of local people in connection with pesticide use; to understand the local farmers' views on the impact of pesticides on the environment and ecosystem; to assess the knowledge, attitude, and behavior of local farmers regarding the safe use of pesticides; to compare the differences in knowledge and behavior between local farmers from two socially differentiated counties; and if possible, to reveal the main reasons that hinder the safe use of pesticides.

\section{The study area}

To restrict the extent of the area of investigation, the authors selected the Guanting Reservoir area for case study $\left(115^{\circ} 30^{\prime} \mathrm{E}\right.$ to $116^{\circ} \mathrm{E}$ longitude and $40^{\circ} 10^{\prime} \mathrm{N}-$ $40^{\circ} 35^{\prime} \mathrm{N}$ latitude). The Guanting Reservoir, located in the northwest of Beijing, is one of the five major water systems of Beijing. It used to be a drinking water source for Beijing before 1997, but the water quality of the reservoir has been degraded from class II to class IV in terms of the national standards (GHZB 11999) for the following reasons: (1) a variety of small industrial complexes are located in its upper reach and have discharged a large amount of polluted water into the river; (2) a large quantity of domestic sewage is dumped into the water; (3) a decrease in flow of the upper reaches of river because of drought and farm irrigation caused a decrease in the volume of the reservoir; and (4) non-point farming pollution is a big source of Guanting Reservoir contamination (Zhang et al. 2004, 2005a, b).

The Guanting Reservoir is surrounded by two mountainous regions: Yanqing County, Beijing City, and Huailai County, Hebei Province. Agriculture and animal husbandry are the primary occupations of the local people. Huailai County is less developed than Yanqing County. The geographical location is shown in Fig. 1.

\section{Research methods}

The research was carried out by means of field study, interview, and questionnaires, administered by personal interviews. Data were collected in 2005, in 15 villages around the Guanting Reservoir that belong to Huailai County and Yanqing County. The 15 villages were selected by the method of quota sampling according to regional distribution.

Standardized questions and answers were placed in a questionnaire. The questions involved the knowledge, attitudes, and protection measures towards pesticides. Single choice and multiple choices were set respectively based on the questions. The questionnaire survey was conducted using random sampling to select 350 farm families from 15 villages. The farmers gave oral consent to participate in the study after hearing an explanation of the study's objective. The respondents clearly knew that the 
Fig. 1 Geographical location of Guanting Reservoir
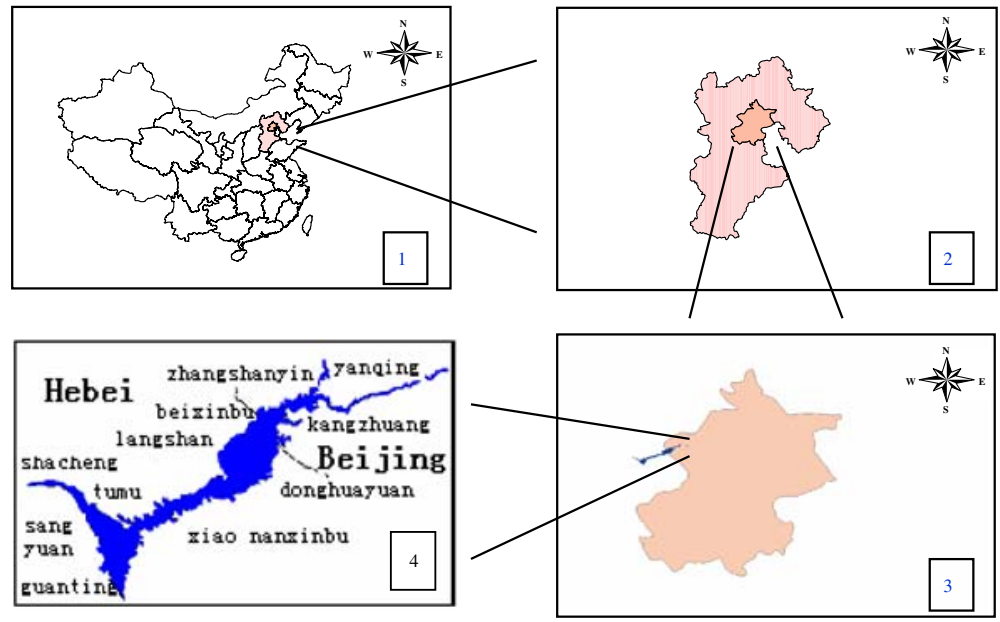

investigating team was pursuing academic research and was in no way directly related to the management authority of any of the administrative departments. A trained interviewer (a local student) asked the questions in the local language. The head of each household was selected as the respondent on the assumption that the behavior of a family is determined by the head's attitude and intention.

The data collected from the questionnaires are summarized in Tables 2-4. Data entry and statistical analysis were conducted with SPSS software. A $\chi^{2}$ test was used for dichotomous qualitative variables or nominal qualitative variables, with an admitted $\alpha$ error of 5\% (Wang 2003; Deng et al. 2002).

According to the response, an analysis was made focusing on: (1) the source of information that farmers relied on in their use of pesticides; (2) pesticide knowledge and education that farmers understand; (3) prevention measures taken by farmers during their application of pesticides.

\section{Results}

Social and demographic characteristics

The social characteristics of the respondents are given in Table 1 . The questionnaire was conducted with 350 farmer families: 258 responded efficiently enough to be included in the study, so the effectual response rate is $73.7 \%$. Of the 258 respondents, 167 were in Huailai County and the other 91 were in Yanqing County. Of the total respondents, $69.77 \%$ were males and $30.23 \%$ were females. Among the 258 farmer households investigated, the four-person household class was the largest (55.43\%), followed by three-person households and then five-person households. Among the household heads, the 40-50 age class was the largest $(50.78 \%)$, followed by the 30-40 (27.52\%), 20-30 (8.14\%), and over 50 $(13.57 \%)$. As regards their education level, a large proportion $(81.01 \%)$ had received primary or high school education, while $16.28 \%$ attended elementary school only and just $2.71 \%$ attended college.

The knowledge of local people about pesticides

The knowledge and information that local farmers had about pesticides are shown in Table 2. The respondents reported that pesticide information was most often received through oral communication with co-workers $(55.43 \%)$ and experience $(41.09 \%)$. Pesticide distributors were another source of information $(34.50 \%)$. Lower proportions reported receiving information from a specialist $(10.85 \%)$, or through learning by TV (25.79\%), newspaper $(16.67 \%)$, or Internet $(7.36 \%)$. A $\chi^{2}$ test was performed, and it indicated that there is a statistically significant difference between Huailai County and Beijing City $(P<0.05)$.

In response to the question "Do you believe pesticides are dangerous or not?", a majority of $61.24 \%$ of people, who selected 'extremely dangerous' or 'dangerous', considered that pesticides were dangerous for human beings and animals, while 
Table 1 Characteristics of the sample

\begin{tabular}{llrrllrr}
\hline Category & & N & \multicolumn{1}{l}{$\%$} & Category & & $\%$ \\
\hline District & Beijing & 91 & 35.27 & Number of people & 2 & 10 & 3.88 \\
& Hebei & 167 & 64.73 & in household & 3 & 50 & 19.38 \\
\multirow{2}{*}{ Sex } & Male & 180 & 69.77 & & 4 & 143 & 55.43 \\
& Female & 78 & 30.23 & & 5 & 38 & 14.73 \\
Age & $18-30$ & 21 & 8.14 & & 6 & 17 & 6.59 \\
& $30-40$ & 71 & 27.52 & Education level & Primary school & 42 & 16.28 \\
& $40-50$ & 131 & 50.78 & & Middle school & 108 & 41.86 \\
& $50-$ & 35 & 13.57 & & High school & 101 & 39.15 \\
& & & & & College and over & 7 & 2.71 \\
\hline
\end{tabular}

$11.63 \%$ of people thought there was slight danger. Moreover, most of the farmers reported a lack of adequate information. The responses were on a fourpoint scale of 'know little,' 'know a little,' 'know well,' and 'know very well.' Of them, $17.44 \%$ responded that they knew little, $56.59 \%$ that they knew a little, $19.38 \%$ that they knew well, and only $4.26 \%$ that they knew very well. Most of them did not know the chemical names of pesticides, and $62.79 \%$ of them could not name any banned pesticides.

Certified pesticides are required to meet certain qualifications in China. When asked about whether the respondents know these qualifications, $60.08 \%$ of them answered yes and $39.53 \%$ no. A $\chi^{2}$ test showed that there was a statistically significant difference between Huailai County and Beijing City $(P<0.05)$, and farmers in Beijing City knew more about pesticide qualifications than those in Hebei Province. However, even those who answered yes did not know all of the qualifications of certified pesticides, because when we asked them to note all of the qualifications of pesticides, they could not specify them accurately.

Pesticide management regulations and provisions have been revised several times in China, but the situation in the countryside is still in chaos ( $\mathrm{Li}$ et al. 2002; Yao 2001). Given a four-point scale from 'know little' to 'know very well' on the question 'Do you know the pesticide laws and management policies of China?', $24.42 \%$ of respondents indicated that they knew little about pesticide policy, $63.57 \%$ that they knew a little, $5.81 \%$ that they knew well, and only $4.26 \%$ that they knew very well. The farmers are indifferent and passive to learning about pesticide policy from a conversational approach.
End-users' attitude and behavior towards pesticides

The end-users' attitudes and behavior towards purchasing and applying pesticides are given in Table 3 . Farms could buy pesticides from several sections such as pesticide enterprises and agro-technical stations. It was reported that farmers bought pesticides from special agribusiness (42.64\%), agrotechnical stations $(29.46 \%)$, plant protection stations $(14.73 \%)$, soil fertilizer stations $(11.24 \%)$, and pesticide enterprises $(9.69 \%)$. Also, $25.19 \%$ of them bought pesticides from grocery stores, which mainly sell foodstuffs and household supplies and have no certification to sell pesticides.

With regard to the question "How do farmers choose which kind of pesticide to buy?", $44.57 \%$ of the respondents reported that they chose pesticides based on recommendations of acquaintances, $40.70 \%$ based on recommendations of salesmen, $33.33 \%$ based on recommendations of technicians, $32.56 \%$ according to their own experience and fancy, and $10.47 \%$ of them according to advertisements. We can conclude that when a new pesticide is introduced to local people, the advice of salesmen and technicians strongly effects the decisions of end-users.

'When do farmers apply pesticides on their farmland?' The survey data revealed that $41.09 \%$ of farmers use pesticides immediately after insects appear, $34.50 \%$ of them spray pesticides ahead of schedule for prevention, $9.69 \%$ of them apply when others spray, and $7.75 \%$ of them apply when their crop is severely infested by pests. In the event that the pesticides the farmers use fail to control pests effectively, $42.25 \%$ of the farmers indicated that they would change to another kind of pesticide, 
Table 2 The knowledge of local people about pesticide

\begin{tabular}{|c|c|c|c|}
\hline Questions & Variables & $\mathrm{N}$ & $\%$ \\
\hline \multirow{7}{*}{$\begin{array}{l}\text { How do you get information about pesticides? } \\
\chi^{2}=23.031 *\end{array}$} & TV & 67 & 25.97 \\
\hline & Books & 43 & 16.67 \\
\hline & Internet & 19 & 7.36 \\
\hline & Oral communication & 143 & 55.43 \\
\hline & From a specialist & 28 & 10.85 \\
\hline & Pesticide distributors & 89 & 34.50 \\
\hline & By experience & 106 & 41.09 \\
\hline \multirow{2}{*}{$\begin{array}{l}\text { To what extent have you mastered pesticide knowledge, } \\
\text { such as name, toxicity, and effect? }{ }^{\mathrm{a}}\end{array}$} & Know little & 45 & 17.44 \\
\hline & Know a little & 146 & 56.59 \\
\hline \multirow[t]{2}{*}{$\chi^{2}=0.658$} & Know well & 50 & 19.38 \\
\hline & Know very well & 11 & 4.26 \\
\hline \multirow{5}{*}{$\begin{array}{l}\text { Do you believe pesticides are dangerous or not? }{ }^{\mathrm{a}} \\
\chi^{2}=1.321\end{array}$} & Extremely dangerous & 54 & 20.93 \\
\hline & Dangerous & 104 & 40.31 \\
\hline & Moderately dangerous & 69 & 26.74 \\
\hline & Slightly dangerous & 30 & 11.63 \\
\hline & Not dangerous & 0 & 0.00 \\
\hline \multirow{4}{*}{$\begin{array}{l}\text { Do you know what pesticides are banned by the government? } \\
\chi^{2}=9.426^{*} \\
\text { Do you know the qualifications of certified pesticides? } \\
\text { If you answer yes, please note them. }{ }^{\mathrm{a}}\end{array}$} & No & 95 & 36.82 \\
\hline & Yes & 162 & 62.79 \\
\hline & No & 102 & 39.53 \\
\hline & Yes & 155 & 60.08 \\
\hline \multicolumn{4}{|l|}{$\chi^{2}=4.417 *$} \\
\hline \multirow{4}{*}{$\begin{array}{l}\text { Do you know the pesticide laws and management policies of China? } \\
\chi^{2}=2.16\end{array}$} & Know little & 63 & 24.42 \\
\hline & Know a little & 164 & 63.57 \\
\hline & Know well & 15 & 5.81 \\
\hline & Know very well & 11 & 4.26 \\
\hline
\end{tabular}

$* P<0.05$

a Single choice

b Multiple choice

$24.03 \%$ of them would increase dosages or frequency of application, and $24.03 \%$ of them would ask others for suggestions. Using pesticides in the proper season or according to pest forecasts is most important for reducing the dosage and frequency of pesticides. Changing pesticide dosage or switching to another kind can change the dose required to kill pests and increase pests' resistance to the pesticides. Laboratory experiments show that pesticides can cause health problems such as birth defects, nerve damage, cancer, and other effects that might occur over a long time (Van Dijk 2000; Bruce 2002). However, these effects depend on how toxic the pesticide is and how much of it is consumed. Consequently, local department and end-users should carefully regulate pesticides to ensure that their use does not pose unreasonable risks to human health or the environment.

Most farmers reported that they had bought counterfeit pesticides at least once. The primary reason (47\%) was the inability to distinguish between genuine and counterfeit pesticides. Despite a series of rules and regulations intended to address the production, distribution, and management of pesticides that have been established in China, insufficient execution often leads to poor results. Some pesticide producers or distributors do not have complete qualifications, or their qualifications are no longer valid (Wang and Tan 2002). Moreover, pesticide companies hide the true name of the prepared product, use unclear labels, and made any pesticide, even forbidden pesticides, readily 
Table 3 End-users' attitude and behavior towards pesticides

\begin{tabular}{|c|c|c|c|}
\hline Questions & Variables & $\mathrm{N}$ & $\%$ \\
\hline Where do you buy pesticides? ${ }^{\mathrm{b}}$ & Special agribusiness & 110 & 42.64 \\
\hline \multirow[t]{6}{*}{$\chi^{2}=21.852^{* *}$} & Agro-technical station & 76 & 29.46 \\
\hline & Grocery & 65 & 25.19 \\
\hline & plant protection station & 38 & 14.73 \\
\hline & Soil fertilizer station & 29 & 11.24 \\
\hline & Pesticide enterprise & 25 & 9.69 \\
\hline & Other & 12 & 4.65 \\
\hline \multirow{6}{*}{$\begin{array}{l}\text { How do you choose which type of pesticide to use? } \\
\chi^{2}=17.641^{* *}\end{array}$} & Rely on experience and fancy & 84 & 32.56 \\
\hline & Listen to acquaintances' recommendations & 115 & 44.57 \\
\hline & Listen to salesmen's recommendations & 105 & 40.70 \\
\hline & Listen to technicians' recommendations & 86 & 33.33 \\
\hline & According to Advertisements & 27 & 10.47 \\
\hline & Other & 13 & 5.04 \\
\hline \multirow{5}{*}{$\begin{array}{l}\text { When do you apply pesticides? } \\
\chi^{2}=28.184^{*} *\end{array}$} & Ahead of schedule to prevent & 89 & 34.50 \\
\hline & Apply immediately after pests appear & 106 & 41.09 \\
\hline & Apply when pests infestation is severe & 20 & 7.75 \\
\hline & Apply when others use & 25 & 9.69 \\
\hline & Other & 14 & 5.43 \\
\hline \multirow{4}{*}{$\begin{array}{l}\text { What would you do if the pesticides had no effect? } \\
\chi^{2}=31.871^{*} *\end{array}$} & Increase dosages or frequency & 62 & 24.03 \\
\hline & Switch to another pesticide & 109 & 42.25 \\
\hline & Ask others & 62 & 24.03 \\
\hline & Other & 19 & 7.36 \\
\hline \multirow{2}{*}{$\begin{array}{l}\text { Have you bought counterfeit pesticides? } \\
\text { If yes, please answer why. }\end{array}$} & Cannot distinguish & 121 & 46.90 \\
\hline & Counterfeits are cheaper & 28 & 10.85 \\
\hline \multirow[t]{2}{*}{$\chi^{2}=39.48 * *$} & Counterfeits are effective & 10 & 3.88 \\
\hline & Other & 30 & 11.63 \\
\hline
\end{tabular}

$* * P<0.01$

a Single choice

b Multiple choice

available to the end-users without prescription (Geng and Shen 2002).

A $\chi^{2}$ test was performed on these questions and indicated that there was a statistically significant difference between Huailai County and Beijing City $(P<0.05)$. It seemed that Beijing farmers were better informed than Hebei farmers, and as such they made more informed choices when they bought or used pesticides.

Protection measures and environmental safety measures by pesticide end-users

The pesticide end-users' protection measures and environmental safety measures are given in
Table 4. The adverse influences of pesticides on human health and the environment were widely known by the farmers in the studied area. Of them, $79.46 \%$ took some prevention measures, while $18.22 \%$ took few.

Some specific prevention measures taken by farmers are presented in Table 4. Of the farmers, $61.24 \%$ took a shower immediately after their work shift, $60.08 \%$ did not eat food or smoke during application, and $53.49 \%$ stored pesticides away from food. But other protective measures, like wearing special preventive masks and gloves during application and stopping working when feeling a slight discomfort were not focused on enough by farmers. Asked further why they did not take these protective 
Table 4 Pesticides end-users' protection measures and environmental safety measures

\begin{tabular}{|c|c|c|c|}
\hline Questions & Variables & $\mathrm{N}$ & $\%$ \\
\hline Do you take prevention measures when you apply pesticides? ${ }^{\mathrm{a}}$ & Yes & 205 & 79.46 \\
\hline$\chi^{2}=1.899$ & Seldom & 47 & 18.22 \\
\hline If you said "yes", please mark which measures you take. & Take a shower after work & 158 & 61.24 \\
\hline \multirow[t]{6}{*}{$\chi^{2}=22.317 * *$} & Do not eat, drink or smoke during work & 155 & 60.08 \\
\hline & Separate clothes while cleaning & 108 & 41.86 \\
\hline & Wear special prevention masks and gloves & 40 & 15.50 \\
\hline & Stop working if feel uncomfortable & 79 & 30.62 \\
\hline & Store pesticides away from food & 138 & 53.49 \\
\hline & Apply according to directions strictly & 98 & 37.98 \\
\hline \multirow{2}{*}{$\begin{array}{l}\text { If you said "seldom" or indicated that you took } \\
\text { fewer than } 3 \text { items, please give your reasons. }\end{array}$} & Not enough money to buy prevention masks & 34 & 13.18 \\
\hline & Feel trouble when prepare and use & 39 & 15.12 \\
\hline \multirow[t]{2}{*}{$\chi^{2}=9.063$} & Think pesticides aren't harmful & 70 & 27.13 \\
\hline & Take actions as others & 31 & 12.02 \\
\hline How do you dispose of the containers? ${ }^{\mathrm{a}}$ & Discard containers into the environment & 134 & 51.94 \\
\hline \multirow[t]{4}{*}{$\chi^{2}=30.6 * *$} & Sell containers to junk dealers & 61 & 23.64 \\
\hline & Return containers to pesticide distributors & 29 & 11.24 \\
\hline & Use containers for storing other things & 8 & 3.10 \\
\hline & Other & 22 & 8.53 \\
\hline
\end{tabular}

$* * \mathrm{P}<0.01$

a Single choice

a Multiple choice

measures, $27.13 \%$ of farmers considered that contact with pesticides was not extremely dangerous and that taking just a little care was okay; $15.02 \%$ thought wearing and using protective cloth and facilities was too much trouble; $13.18 \%$ said they could not afford to purchase protective masks; and $12.02 \%$ said they just follow the ideas and behaviors of the majority.

The disposal of containers after use was also investigated. The majority of farmers (51.94\%) would discard pesticide containers into the environment (soil or water) or with other trash. Of the farmers, $11.24 \%$ returned empty containers to the pesticide distributors. Of them, 23.64\%disposed of empty containers to junk dealers. It is worth noting that $3.1 \%$ of them used containers for storing other things. A $\chi^{2}$ test indicated that there was a statistically significant difference between respondents from Huailai County and Beijing City $(P<0.05)$. Of Hebei farmers, $63.47 \%$ chose 'discard pesticide containers into the environment,' while among Beijing farmers $31.87 \%$ chose 'dispose of empty containers to junk dealers' and $30.77 \%$ chose 'discard pesticide containers into the environment.'

\section{Conclusions}

The results reveal that investigation into local pesticide end-users' attitude and practice can produce useful information that can be incorporated into the decision-making process leading to pesticide management. The findings indicate that local farmers have no extensive knowledge of pesticides. They are either unmotivated to learn about pesticides or they do not know how best to obtain knowledge about pesticides. An active and effective training of endusers by local government could help in promoting knowledge of pesticides. Occupational safety and health interventions should be involved.

The results show that local farms can buy pesticides from several agents such as pesticide enterprises, agro-technical stations, and grocery stores. Most farmers selected pesticide types based on the recommendations of acquaintances or salesmen. Pesticide end-users lack adequate knowledge to identify counterfeit pesticides. Of them, $47 \%$ had bought counterfeit pesticides at least once. The results might be useful for the local government to 
control the admission of pesticides into markets and to regulate pesticide production and distribution.

The findings also indicate that a majority of farmers take prevention measures when they use pesticides. However, they do not take all necessary protective measures and thus expose themselves to higher health risks than the general population. Their attitudes toward pesticide safety and health effects vary widely. They seem to be unaware of real pesticide risks and lack safety education.

Results of a $\chi^{2}$ test indicated that there is a statistically significant difference between Huailai County and Beijing City in the knowledge and use of pesticides. Beijing farmers are better informed than Hebei farmers, and as such they make more informed choices when they buy or use pesticides.

This paper is intended to reveal the main reasons behind the unsafe use of pesticides. It seems that bad training of farmers and insufficient management of local organizations are significant obstacles. Although a series of pesticide-related laws and regulations have been promulgated in China, insufficient execution and some shortcomings of many regulations themselves have often led to poor results. This study provides compelling evidence that the supervision mechanism for pesticide management over environmental monitoring systems should be enhanced.

Acknowledgements We thank local school teachers for their tireless assistance and immeasurable help in the field survey. Funding for this research came from the Knowledge Innovation Program of the Chinese Academy of Sciences, with grant no. KZCX2-414, and the National Basic Research Program 973, with grant no. $2007 \mathrm{CB} 407307$.

\section{References}

Bruce, D. R. (edit) (2002). The foundation for global action on persistent organic pollutants: a United States perspective. Washington: EPA, Office of Research and Development. http://www.epa.gov

Deng, Z., Yao, S., \& Sun, J. (2002). The methods of analysis qualitatively of questionnaire investigation and its application. Jiangsu Statistical Research, 12, 21-22.
Geng, J., \& Shen, W. (2002). The problems existed in the safety usage of pesticides and the countermeasure. Anhui Agricultural Science, 30(1), 139-141.

GHZB 1-1999. Environmental quality standard for surface water[S]. 2000.

Gomes, J., Lloyd, O. L., \& Revitt, D. M. (1999). The influence of personal protection, environmental hygiene and exposure to pesticides on the health of immigrant farm workers in a desert country. International Archives of Occupational and Environmental Health, 72, 40-45.

Koh, D., \& Jeyaratnam, J. (1996). Pesticide hazards in developing countries. The Science of the Total Environment, 188, S78-S85.

Li, Z., Ning, D., \& Guo, X. (2002). Pesticides market management. Pesticides Science and Management, 23(4), 3739.

Pascale, R. S., Isabelle, B., Patrick, B., \& Bernadetta, A. S. (2004). Pesticides in Lebanon: A knowledge, attitude, and practice study. Environmental Research, 94, 1-6.

Salameh, P. R., Baldi, I., Brochard, P., \& Saleh, B. A. (2004). Pesticides in Lebanon: a knowledge, attitude, and practice study. Environmental Research, 94, 1-6.

Sewell, W. R. W. (1973). Broadening the approach to evaluation in resource management decision making. Journal of Environmental Management, 1, 33-60.

Van Dijk, H. F. G., Brussaard, L., Stein, A., Baerselman, F., et al. (2000) Field research for the authorisation of pesticides. Ecotoxicology, 9(6), 377-381.

Wang, P., \& Tan, X. (2002). The condition of the pesticides market and analysis of the measurement. Economic Problems of Agriculture, 8, 61-63.

Wang, Y. (2003). The quality control of the questionnaire investigation. Business Economy and Management, 138(4), 25-27.

White, G. F. (1966). Formation and role of public attitudes. In H. Farrett (Ed.), Environmental quality in a growing economy (pp. 105-109). Baltimore, Maryland: John Hopkins Press.

Yao, J. (2001). The suggestions of the pesticides management. Pesticide Science and Management, 22(2), 39-40.

Zhang, H., Lu, Y., Shi, Y., et al. (2005a). Legal Framework related to Persistent Organic Pollutants (POPs) management in China. Environmental Science and Policy, 8, 153160 .

Zhang, H., Lu, Y., Shi, Y., et al. (2005b). Classification and ordination of DDT and $\mathrm{HCH}$ in soil samples in Guanting Reservoir areas. Chemosphere, 60(6), 762-769.

Zhang, H., Lu, Y., Wang, T., et al. (2004). Accumulation features of organochlorine pesticides residues in soils around Beijing Guanting Reservoir. Bulletin of Environment Contamination and Toxicology, 72, 954-961. 